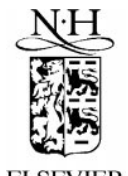

International Journal of Industrial Organization

16 (1998) 271-284

\title{
The incentive for non-price discrimination by an input monopolist
}

\author{
Nicholas Economides* \\ Stern School of Business, New York University, New York, NW 10012, USA
}

Received 1 May 1997; received in revised form 30 November 1997; accepted 16 January 1998

\begin{abstract}
This paper considers the incentive for non-price discrimination of a monopolist in an input market who also sells in an oligopoly downstream market through a subsidiary. Such a monopolist can raise the costs of the rivals to its subsidiary though discriminatory quality degradation. I find that the monopolist always, even when it is cost-disadvantaged, has the incentive to raise the costs of the rivals to its subsidiary in a discriminatory fashion, but does not have the incentive to raise costs to the whole downstream industry including its subsidiary. Moreover, increasing rivals' costs nullifies the effects of traditional imputation floors, and prompts the creation of imputation floors that account for the artificial costs imposed on downstream rivals. The results of this paper raise concerns about the potentially anti-competitive effects of entry of local exchange carriers in long distance service. The results may also suggest the imposition of certain unbundling and technical specification disclosure requirements to monopolists in high technology industries. (C) 1998 Elsevier Science B.V.
\end{abstract}

Keywords: Monopoly; Discrimination; Vertical integration

JEL classification: L1; D4

\section{Introduction}

Often, a vertically integrated firm sells its upstream output to its downstream

\footnotetext{
*Tel.: + 1212 9980864; fax: +1 212 9954218; e-mail: neconomi@stern.nyu.edu; www: http://raven.stern.nyu/networks
} 
competitors. In some cases, the downstream competitors have little choice but to buy the input from their competitor because this integrated firm dominates or monopolizes the market for that essential input to the downstream firms. For example, before the 1984 divestiture, AT\&T dominated local access markets in US telecommunications, and its competitor in the long distance market, MCI, had to buy access and termination of calls from AT\&T. Currently, Microsoft dominates the operating systems market for personal computers, but competes with many other firms in the complementary markets for applications software. In US telecommunications, local exchange (long distance) carriers ("LECs") that monopolize the local access markets, are presently proposing to enter long distance service and compete with a number of interexchange carriers ("IXCs").

In this paper, I focus on a vertically integrated firm with very significant market power in the market of an essential input for a downstream market where the integrated firm faces a number of independent competitors. It has been alleged that such a vertically integrated firm will use its market power to impose discriminatory costs on the competitors of its downstream subsidiary. Such costs may arise in a number of ways, including poor quality of interconnection in telecommunications, delays in processing orders, etc. ${ }^{3}$ In the computer software market, costs of competitors may be raised through the creation of incompatibilities ${ }^{4}$ or by the incorporation in the operating system of "hidden" features that are helpful to complementary applications and are disclosed to the monopolist's subsidiary, but are not disclosed to downstream competitors.

A monopolist can also design the monopolized product to include functions that are also provided independently by competitors. For example, Microsoft has integrated Internet Explorer 4 with Windows Explorer and made it part of the

\footnotetext{
${ }^{1}$ LECs are proposing to enter the long distance market under provisions of sections 271 and 272 of the Telecommunications Act of 1996 that allow a LEC to enter long distance in its own region if it meets a checklist of requirements and if it can show that such entry is in the public interest. The 14-point checklist states the minimal requirement that the LEC's local exchange market has been opened to competition. Up to now, all attempts by LECs to be allowed by the FCC to enter long distance (Ameritech in Michigan, SBC in Oklahoma, BellSouth in South Carolina and Louisiana) have been unsuccessful. In all these attempts, the Department of Justice recommended against entry and the FCC decided against entry for two reasons: (i) because the petitioning firm had not successfully fulfilled the checklist; and (ii) because the petitioner had not proved that entry was in the public interest. The author of this article has argued against the Ameritech Michigan application on the basis of the argument of raising rivals' costs as discussed in this paper.

${ }^{2}$ See Beard et al. (1996); Bernheim and Willig (1996).

${ }^{3}$ Such allegations are most pronounced in markets with "light-handed" regulation, such as New Zealand. In New Zealand, the entrants, Clear Communications and BellSouth New Zealand have alleged that Telecom New Zealand, the monopolist local exchange carrier, has delayed and thwarted their attempts to introduce new innovative services. See New Zealand Ministry of Commerce (1995). For allegations of raising rivals costs in the US telecommunications market see Bernheim and Willig (1996).

${ }^{4}$ See Economides (1996).
} 
operating system Windows 95 which it monopolizes. It has been alleged that, by not allowing competitors in the browser market, such as Netscape Navigator, to also seamlessly integrate their browsers into the operating system, Microsoft is essentially providing a lower quality operating system when used with other browsers than when used with Internet Explorer 4. Even when Internet Explorer is not integrated in the operating system, the exclusive installation of it on a new computer by the manufacturer may increase the cost of a rival browser if there is some cost (or time or expertise) required for other browsers to be installed by the user. $^{5}$

Intuitively, it seems plausible that a firm with market power will try to "soften" competition for its downstream subsidiary by increasing the costs of its rivals. Beard et al. (1996) argue strongly in favor of this point of view, and present a model demonstrating the incentive of a regulated dominant firm to engage in anti-competitive "sabotage" against downstream rivals. On the other hand, Sibley and Weisman (1995) claim that, once a LEC starts providing long distance service, it will not have an incentive to raise the costs of long distance companies that are rivals to its subsidiary, even when the vertically integrated LEC is a monopolist in the essential input (local exchange) market.

This paper finds that a monopolist in the essential input market has an incentive to practice non-price discrimination against its downstream rivals. The monopolist raises the costs of its downstream rivals (or, equivalently, reduces the quality of the monopolized product offered to them) until they are driven out of business. This result is established under very general demand conditions. In the special case when the downstream demand is linear, this result is established for any parameter values that fulfill second order conditions.

The rest of the paper is organized as follows. Section 2 describes the basic model. Section 3 describes the incentive for a monopolist to increase the cost of rivals to its subsidiary. Section 4 describes the same incentive when the monopolist faces different costs than the incumbent. The same section discusses the incentive for a monopolist to increase cost to all downstream firms, including its subsidiary. Section 5 describes the consequences of raising rivals costs on the effectiveness of imputation rules. Section 6 contains concluding remarks.

\footnotetext{
${ }^{5}$ On October 20, 1997, the United States Department of Justice (1997) ("DOJ") asked the Federal District Court in Washington DC to find Microsoft in contempt of the consent decree that DOJ and Microsoft had reached at the end of a monopolization suit by the DOJ against Microsoft in 1994. Among others, the consent decree required that Microsoft not require makers of personal computers (Original Equipment Manufacturers, "OEMs") to buy any other Microsoft product when they bought Windows95. In the October 20, 1997 petition for contempt, the DOJ alleges that Microsoft was requiring OEMs to install Internet Explorer if they installed Windows95 in new computers. The results of this paper show that Microsoft has an incentive to impose this requirement on OEMs so that rivals' costs are raised. Microsoft's defence is that Internet Explorer is an integral part of Windows95. Moreover, extensions and improvements of the operating system are allowed under the consent decree.
} 


\section{The model}

Suppose that an upstream market is a monopoly and a downstream market is a $n$-firm oligopoly. Suppose further that one of the $n$ firms is a subsidiary of the upstream monopolist. The monopolist sells the monopolized input at a nondiscriminatory price of $w$. The monopolist can impose an extra cost to the rivals of its subsidiary, equal to $r$. This extra cost arises out of quality degradation, delays, etc., and is not realized as a revenue by the upstream firm. I investigate the incentives for the monopolist to impose a positive cost, $r>0$, to the rivals of its subsidiary.

\subsection{The upstream market}

I assume that the upstream monopolist has fixed cost $F^{\mathrm{U}}$, constant marginal cost $c$ and sells all units at price $w$. Suppose that the output of the upstream market is needed by the downstream production process in constant ratio with the downstream output. I normalize units so that one unit of the upstream output in used in one unit of downstream output. Let the inverse demand for the output of the downstream market be $p(Q)$ where

$$
Q=q_{1}+\Sigma_{i \neq 1} q_{i} \text {. }
$$

Then the profits of the monopolist from the upstream market are

$$
\Pi_{1}^{\mathrm{U}}=(w-c) Q-F^{\mathrm{U}} .
$$

\subsection{The downstream market}

The downstream market consists of the subsidiary of the upstream monopolist (firm 1) as well as $n-1 \geqslant 1$ independent competitors. Let the marginal cost of inputs to a downstream firm other than those bought from the upstream monopolist be denoted by $s$, and assume that units are normalized so that one unit of upstream input is used for one unit of downstream output. Then the downstream profits of the monopolist's subsidiary are

$$
\Pi_{1}^{\mathrm{D}}=(p-s-w) q_{1}-F^{\mathrm{D}},
$$

so that overall profits of the vertically integrated monopolist are

$$
\Pi_{1} \equiv \Pi_{1}^{\mathrm{U}}+\Pi_{1}^{\mathrm{D}}=(w-c) Q+(p-s-w) q_{1}-\left(F^{\mathrm{U}}+F^{\mathrm{D}}\right) .
$$

Independent downstream firms face an extra cost, denoted by $r$, that reflects the actions of the upstream monopolist to raise the costs of the rivals of its subsidiary through quality degradation and other actions. Thus, a typical independent firm $i$ has profits 


$$
\Pi_{i} \equiv \Pi_{i}^{\mathrm{D}}=(p-s-w-r) q_{i}-F^{\mathrm{D}}
$$

\section{Equilibrium for general demand}

I assume that the downstream market is a Cournot oligopoly. Profit maximization by firm 1 on the choice of $q_{1}$ requires: $^{6}$

$$
\mathrm{d} \Pi_{1} / \mathrm{d} q_{1}=p+q_{1} p^{\prime}(Q)-(c+s)=0 .
$$

Profit maximization by firm $i \neq 1$ on the choice of $q_{\mathrm{i}}$ requires: $^{7}$

$$
d \Pi_{i} / d q_{i}=p+q_{i} p^{\prime}(Q)-(w+s+r)=0 .
$$

Thus, the marginal cost to an independent firm (rival) is higher than to the subsidiary of the monopolist. This is for two reasons: first, the cost of the upstream input is effectively higher for the rivals, $w>c$; second, because of the extra cost $r$ imposed exclusively on the rivals, their cost is higher. Nevertheless, it is clear that the rivals face higher upstream input cost than the subsidiary even in the absence of non-price discrimination, i.e., when $r=0$. This occurs despite the fact that, on the surface, the monopolist sells to all downstream firms at the same price $w$. As a direct consequence of facing lower marginal cost, the monopolist's subsidiary produces more in equilibrium than an independent firm, $q_{1}>q_{i}$.

Let the Cournot equilibrium quantities that solve Eq. (6) and Eq. (7) be $q_{1}=q_{1}^{*}$, $q_{i}=q_{i}^{* 8}$, and, similarly, denote the industry equilibrium sales by $Q^{*}=q_{1}^{*}+(n-$ 1) $q_{i}^{*}$. To define industry output without reference to individual firms' outputs, multiply Eq. (7) by $n-1$ and add to Eq. (6):

$$
n p\left(Q^{*}\right)+Q^{*} p^{\prime}\left(Q^{*}\right)=n s+c+(n-1)(w+r) .
$$

The equilibrium profits of firm 1 are:

$$
\Pi_{1}^{*}=(w-c) Q^{*}+(p-s-w) q_{1}^{*}-\left(F^{\mathrm{U}}+F^{\mathrm{D}}\right) .
$$

By definition, the upstream monopolist has an incentive to raise rivals costs by $r>0$ if there exists an $r>0$ such that $\Pi_{1}^{*}(r)>\Pi_{1}^{*}(0)$. The incentive that the upstream monopolist has to marginally increase the costs of the rivals of its downstream subsidiary is measured by

$$
\mathrm{d} \Pi_{1}^{*} / \mathrm{d} r=(w-c)\left(\mathrm{d} Q^{*} / \mathrm{d} r\right)+\left(q_{1}^{*} p^{\prime}\right)\left(\mathrm{d} Q^{*} / \mathrm{d} r\right)+(p-s-w)\left(\mathrm{d} q_{1}^{*} / \mathrm{d} r\right) .
$$

\footnotetext{
${ }^{6}$ The second order condition is $\mathrm{d}^{2} \Pi_{1} / \mathrm{d} q_{1}^{2}=2 p^{\prime}+q_{1} p^{\prime \prime}<0$.

${ }^{7}$ The second order condition is $\mathrm{d}^{2} \Pi_{i} / \mathrm{d} q_{i}^{2}=2 p^{\prime}+q_{i} p^{\prime \prime}<0$.

${ }^{8}$ Inspection of equation (7) implies that all independent firms produce equal amounts.
} 
Since there are no closed form solutions for the case of general demand, I calculate $\mathrm{d} Q^{*} / \mathrm{d} r$ and $\mathrm{d} q_{1}^{*} / \mathrm{d} r$ from the system of the first order conditions. Totally differentiating Eq. (8) implies

$$
\mathrm{d} Q^{*} / \mathrm{d} r=(n-1) /\left[(n+1) p^{\prime}+Q^{*} p^{\natural}\right] .
$$

This is negative when

$$
(n+1) p^{\prime}+Q^{*} p^{\prime}<0 .
$$

Condition Eq. (12) is a standard regularity condition in Cournot oligopoly that is equivalent to an equal increase in marginal cost of all firms resulting in a decrease in output and an increase in price, i.e.,

$$
\mathrm{d} Q^{*} / \mathrm{d} s<0 \Leftrightarrow \mathrm{d} p\left(Q^{*}\right) / \mathrm{d} s>0 \Leftrightarrow(n+1) p^{\prime}+Q^{*} p^{\prime}<0 \Leftrightarrow \mathrm{d} Q^{*} / \mathrm{d} r<0 .
$$

Total differentiation of Eq. (6) implies

$$
\mathrm{d} q_{1}^{*} / \mathrm{d} r=-\left(\mathrm{d} Q^{*} / \mathrm{d} r\right)\left(p^{\prime}+q_{1}^{*} p^{\prime}\right) / p^{\prime} .
$$

This is positive, given $\mathrm{d} Q^{*} / \mathrm{d} r<0$, when

$$
p^{\prime}+q_{1}^{*} p^{\prime}<0 \text {. }
$$

Condition Eq. (15) is also a standard regularity condition in Cournot oligopoly that is equivalent to a downward sloping best reply function of firm 1, or equivalently, that $q_{1}$ and $\Sigma_{i \neq 1} q_{i}$ are strategic substitutes.

I have shown that a discriminatory increase in the cost of downstream rivals results in a decrease in industry output, an increase in final output price, a decrease in the output of each independent firm, and an increase in the output of the monopolist's subsidiary. An increase in $r$ unambiguously reduces welfare since total industry sales are reduced, and a production inefficiency is incurred.

I am now in position to evaluate the incentive of the monopolist to raise the cost of downstream rivals. The total effect of increases in $r$ on profits, $\mathrm{d} \Pi_{1}^{*} / \mathrm{d} r$, can be dissected (from Eq. (10)) in three parts. The first part, $(w-c)\left(\mathrm{d} Q^{*} / \mathrm{d} r\right)<0$, represents the reduction of profits of the monopolist in its upstream operations. The second part, $\left(q_{1}^{*} p^{\prime}\right)\left(\mathrm{d} Q^{*} / \mathrm{d} r\right)>0$, represents the positive effect on the downstream subsidiary's revenues (holding the subsidiary's output constant) precipitated by the downstream price increase that results from increasing the costs of the independent competitors. The third part, $(p-s-w)\left(\mathrm{d} q_{1}^{*} / \mathrm{d} r\right)>0$, represents the increased revenues from expanded sales of the subsidiary, keeping price constant. The essence of the proof that $\mathrm{d} \Pi_{1}^{*} / \mathrm{d} r>0$ relies on the fact that the

\footnotetext{
${ }^{9}$ Note that if condition equation (15) holds, so does condition equation (12). If $p^{\prime \prime}<0$, clearly both conditions hold. If $p^{\prime \prime}>0, q_{1}^{*}>q_{i} \Rightarrow q_{1}^{*}>Q^{*} / n>Q^{*} /(n+1)$, and therefore $p^{\prime}+q_{1}^{*} p^{\prime \prime}>p^{\prime}+\left[Q^{*} /(n+\right.$ 1)] $p^{\prime \prime}$, and the result follows.
} 
combination of the first and the second parts is positive. Since the third part is positive (from the profit maximization condition of the independents), the result follows.

Since $\mathrm{d} Q^{*} / \mathrm{d} r<0$, to prove that the sum of the first and second parts is positive, it is sufficient to prove that $w-c+q_{1}^{*} p^{\prime}<0$. This expression has a simple interpretation: it is the increase in the profits of the integrated monopolist when the downstream total output of all other firms expands by one unit and its own subsidiary's output is held constant. I show that this is negative.

The proof is by contradiction. Suppose not, i.e., suppose that $-w+c-q_{1}^{*} p^{\prime}<0$. Then adding this inequality to Eq. (6), implies $p<s+w$, i.e., that downstream price is below the marginal cost of an independent firm - an impossibility. Thus, the original statement was true:

$$
w-c+q_{1}^{*} p^{\prime}<0 \text {. }
$$

In other words, if increases in downstream output (keeping the subsidiary's output constant) resulted in higher profit for the integrated firm, that would contradict the profit-maximizing existence of downstream competitors. Therefore, increases in downstream output (keeping the subsidiary's output constant) result in decreases of profits for the integrated firm.

Given Eq. (16), the combination of the first and second term in Eq. (10) is positive:

$$
\left(w-c+q_{1}^{*} p^{\prime}\right)\left(\mathrm{d} Q^{*} / \mathrm{d} r\right)>0 .
$$

Since the third term is positive, if follows that $\mathrm{d} \Pi_{1}^{*} / \mathrm{d} r>0$.

This result can also be proved as follows. Profit maximization downstream implies marginal revenue equals marginal cost for every firm. This implies that the difference in marginal cost between an independent firm and the monopolist's subsidiary is equal to the difference in their marginal revenues, i.e.,

$$
M C_{i}-M C_{1}=M R_{i}-M R_{1} \Leftrightarrow w+r-c=\left(q_{i}^{*}-q_{1}^{*}\right) p^{\prime} .
$$

This implies

$$
w-c+q_{1}^{*} p^{\prime}=q_{i}^{*} p^{\prime}-r<0,
$$

and the rest of the proof follows.

Formally, substituting Eq. (14) in Eq. (10):

$$
\begin{aligned}
\mathrm{d} \Pi_{1}^{*} / \mathrm{d} r & =\left(\mathrm{d} Q^{*} / \mathrm{d} r\right)\left[\left(w-c+q_{1}^{*} p^{\prime}-(p-s-w)\left(p^{\prime}+q_{1}^{*} p^{6}\right) / p^{\prime}\right.\right. \\
& =\left(\mathrm{d} Q^{*} / \mathrm{d} r\right)\left(-r+q_{i}^{*} p^{\prime}\right)\left(2+q_{1}^{*} p^{\prime} / p^{\prime}\right)>0,
\end{aligned}
$$

because the first two parentheses are negative and the last one is positive (from 
second order conditions). ${ }^{10}$ Therefore any increase of rivals' costs above zero results in increased profits for the integrated monopolist and subsidiary. Since profits increase with any increase of $r$, the monopolist has the incentive to keep increasing $r$ until the downstream competitors are driven out of business. Finally notice that these results do not depend on the level of the input price $w$ or on the price to cost margin $w-c$ of the input monopolist. I have proved:

Proposition 1. A monopolist in an upstream market has an incentive to increase the costs of rivals to its downstream subsidiary until they are driven out of business. ${ }^{11}$

Proposition 2. Any increase in rival's costs increases the subsidiary's output, decreases the output of rivals, decreases industry output, increases the downstream price, and decreases social welfare. ${ }^{12}$

The effects of raising rivals' costs in the results I present are tempered by the assumption that the number of independent downstream firms is fixed. Essentially I have described a short run equilibrium. In the medium and long run, I expect that the number of firms will adjust in response to the implementation of the strategy of raising rivals' costs. Raising rivals' costs allows the monopolist to "manage" the downstream market and force independents to exit. Thus, in the medium and long run, the consequences of non-price discrimination can be much more adverse to social welfare than the short run consequences that I have described.

The setup this far has been of a discriminatory strategy that increases the costs of downstream rivals but does not affect the demand functions of the subsidiary or of the independents. However, inspection of the profit maximization conditions Eq. (6) and Eq. (7) shows that the results of this paper also hold for a discriminatory degradation of the quality of the input offered to rivals which decreases the willingness to pay for the rivals' downstream output but leaves costs unaffected. In such a setup, independent downstream firms have marginal cost $w+s$, but, since they have a lower quality product, consumers are willing to pay only $p-r$ for their product (while consumers pay $p$ for the subsidiary's output). That is, the independents face a demand curve that is a parallel downward shift by $r$ of the demand faced by the subsidiary. In this setup, clearly the marginal profit of each firm is the same as before, and therefore the equilibrium quantities and

\footnotetext{
${ }^{10}$ In the last step we used the fact that $p-s-w=r-q_{i}^{*} p^{\prime}$ from the profit maximization condition of an independent downstream competitor.

${ }^{11}$ The derivation shows that condition equation (12) (decrease in industry output as a response to a marginal cost increase) is sufficient for the result of Proposition 1.

${ }^{12}$ The derivation shows that condition equation (12) is sufficient for all the results in Proposition 2 except for $\mathrm{d} q_{1}^{*} / \mathrm{d} r>0$ which requires the slightly stronger condition equation (15) of downward slopping best reply for firm 1 .
} 
profits are also the same. Thus, I have proved that the results of Propositions 1 and 2 hold if the strategy of raising rivals' cost is substituted by a discriminatory strategy of degrading the quality of the input supplied to the rivals so that the quality of the output of the rivals is degraded. ${ }^{13}$

\section{Linear demand}

I present here the illustration for the case of linear demand. Of course, this is a special case where $p^{\prime \prime}=0$, and the results of the general case hold. However, the linear case gives us the additional ability to write the equilibrium prices and production in closed form.

In discussing the linear demand case, suppose that the monopolist faces an extra marginal cost $x$ for downstream production. Keeping in mind that $x=0$ represents the standard case, note that $x$ may be positive if the monopolist has a cost disadvantage in the downstream production, or $x$ may be negative when the monopolist has lower costs in the downstream production. The latter is also the case when there are synergies in the joint production of the upstream and downstream components.

The monopolist's profits from downstream operations are now

$$
\Pi_{1}^{\mathrm{D}}=(p-s-w-x) q_{1}-F^{\mathrm{D}},
$$

while all other profit functions remain unaffected. For a linear demand

$$
p=a-b Q
$$

with $a>w+s+r>0, b>0$, the Cournot equilibrium is now: ${ }^{14}$

$$
\begin{aligned}
& q_{1}^{*}=[a-s-c n-n x+(n-1)(w+r)] /[b(n+1)], \\
& q_{i}^{*}=[a+c-s+x-2(w+r)] /[b(n+1)], i \neq 1, \\
& Q^{*}=[(a-s) n-c-x-(w+r)(n-1)] /[b(n+1)], \\
& p^{*} \equiv p\left(Q^{*}\right)=[a+c+n s+x+(n-1)(w+r)] /(n+1),
\end{aligned}
$$

and the realized profits are:

\footnotetext{
${ }^{13}$ See Economides (1998); Economides and Lehr (1995) for a discussion of the quality of goods composed of more than one component.

${ }^{14}$ In comparison to the case of no extra cost to the monopolist $(x=0)$, in the equilibrium with $x>0$, production by independents and market price are higher, while production by the integrated monopolist and industry-wide production are lower.
} 


$$
\begin{aligned}
\Pi_{1}^{\mathrm{U} *}= & (w-c)[(a-s) n-(w+r)(n-1)-c-x] /[b(n+1)]-F^{\mathrm{U}}, \\
\Pi_{1}^{\mathrm{D} *}= & (a+c-s+r(n-1)-2 w-n x)(a-s-c n-n x \\
& +(w+r)(n-1)) /\left[b(1+n)^{2}\right]-F^{\mathrm{D}}, \\
\Pi_{i}^{*}= & (a+c-s+x-2(w+r)]^{2} /\left[b(n+1)^{2}\right]-F^{\mathrm{D}} .
\end{aligned}
$$

The incentive to marginally increase rivals' costs is measured by

$$
\begin{aligned}
\mathrm{d} \Pi_{1}^{*} / \mathrm{d} r & =\mathrm{d}\left(\Pi_{1}^{\mathrm{U} *}+\Pi_{1}^{\mathrm{D} *}\right) / \mathrm{d} r \\
& =2(n-1)[a+c-s+r(n-1)-2 w-n x] /\left[b(n+1)^{2}\right] .
\end{aligned}
$$

Positive production by independent firms implies

$$
q_{i}^{*}>0 \Leftrightarrow w<(a+c+x-s-2 r) / 2 .
$$

Therefore, substituting Eq. (31) in Eq. (30),

$$
\mathrm{d} \Pi_{1}^{*} / \mathrm{d} r>2(r-x)(n-1)(n+1) /\left[b(n+1)^{2}\right] \equiv f(r) .
$$

Thus, when the monopolist has a cost advantage, $x<0$, or when the technologies are the same, $x=0$, the monopolist clearly has an incentive to raise rivals' costs by any feasible $r$, that is, $\mathrm{d} \Pi_{1}^{*} / \mathrm{d} r>0$ for all $r>0$. I next show that, when the monopolist has a cost disadvantage, $x>0$, he also has an incentive to significantly increase rivals' costs.

Considering $\Pi_{1}^{*}$ as a function of $r$, and integrating both sides of Eq. (32), results in

$$
\Pi_{1}^{*}(r)-\Pi_{1}^{*}(0)>\int_{0}^{r} f(r) \mathrm{d} r .
$$

Note that $\int_{0}^{2 \mathrm{x}} f(r) \mathrm{d} r=0$, and $f(r)>0$ for $r>x \geqslant 0$. Therefore, for any $r>2 x$,

$$
\Pi_{1}^{*}(r)-\Pi_{1}^{*}(0)>0+\int_{2 x}^{r} f(r) \mathrm{d} r>0 .
$$

Thus, the monopolist has an incentive to raise rivals' costs by an amount that exceeds twice its own cost disadvantage. Also note that $\mathrm{d}^{2} \Pi_{1}^{*} / \mathrm{d} r^{2}>0$, so that the monopolist has an incentive to increase downstream rivals' costs to higher and higher levels, stopping only when the downstream rivals are out of business. This is an optimal policy from the point of view of the monopolist provided that at $r=2 x$ the sales of the independents from Eq. (24) are positive, i.e., when $a+c-s-2 w>x$.

When the sales of the independents implied by Eq. (24) would be negative at 
$r=2 x$, the optimal policy for the monopolist is to set $r=(a+c-s+x-2 w) / 2$ or higher, so that all competitors are driven out of business, $q_{i}^{*}=0$, and the monopolist remains the only active firm, realizing $q_{1}^{*}=Q^{*}, p^{*}, \Pi_{1}^{\mathrm{U} *}$, and $\Pi_{1}^{\mathrm{D} *}$ from Eq. (23), Eqs. (25)-(28) at $n=1$. Thus, if the cost disadvantage of the monopolist's subsidiary is so large that $r=2 x$ would give negative sales to the independents, the monopolist will increase the rivals costs up to the point at which all independents are driven out of business.

Proposition 3. Even if the monopolist's subsidiary has a cost advantage or disadvantage compared to its rivals, the monopolist still has an incentive to increase the costs of rivals to its downstream subsidiary until they are driven out of business.

It is also easy to show that the strategy of raising rivals costs decreases the rivals' profits, $\mathrm{d} \Pi_{i}^{*} / \mathrm{d} r<0$, but increases the combined profits of the combined upstream and downstream industries, $\mathrm{d}\left(\Pi_{1}^{*}+(n-1) \Pi_{i}^{*}\right) / \mathrm{d} r>0$. Thus, the use of the discriminatory strategy increases the combined profits of the two industries and redistributes profits from the independents to the integrated firm.

I now show that the monopolist does not have an incentive to increase the costs of all downstream firms, including its subsidiary. An increase in all downstream costs is equivalent to increasing cost $s$, since $s$ is faced equally by all firms. The effect on the monopolist's profits is

$$
\mathrm{d} \Pi_{1}^{*} / \mathrm{d} s=-\left\{2\left[p^{*}-(c+x+s)\right]+(w-c)(n-1)\right\} /\left[b(n+1)^{2}\right] .
$$

Thus,

$$
\mathrm{d} \Pi_{1}^{*} / \mathrm{d} s<0
$$

since $p^{*}>c+x+s$ is required for positive production by the integrated firm. Therefore it is not in the integrated monopolist's interest to increase costs to all downstream firms (including its subsidiary).

Proposition 4. The monopolist (even when its downstream subsidiary's costs differ from those of its rivals) has no incentive to increase costs to all downstream firms, including its subsidiary.

In combination with Propositions 1 and 3, Proposition 4 shows that it is desirable for the monopolist to use a discriminatory strategy of raising costs only against the rivals of its subsidiary, rather than to the whole industry.

\section{The effects of raising rivals' costs on imputation}

Imputation has been proposed as a regulatory safeguard against the effects of discrimination. By definition, the regulatory rule of strict imputation imposes a 
price floor for the output of the monopolist's subsidiary, equal to the upstream input price plus the cost of other inputs to a downstream firm. I show next that, when the monopolist raises the costs of its rivals, traditional imputation rules fail to safeguard against discrimination. In particular, I show that imputation fails to safeguard even against foreclosure of downstream rivals. It follows that imputation also fails to safeguard against less extreme effects of discrimination. ${ }^{15}$

An independent firm is foreclosed when the actions of the monopolist make its profits negative. For simplicity, I limit the analysis to the case of zero downstream fixed cost, $F^{\mathrm{D}}=0 .{ }^{16}$ To survive, an independent firm has to have positive production,

$$
q_{i}^{*}>0 \Leftrightarrow a+c>2(w+r)-x+s .
$$

Substituting in Eq. (26), independents' survival implies that the downstream market price should follow

$$
p^{*} \geqslant w+s+r \Leftrightarrow p^{*}-(w+s) \geqslant r,
$$

i.e., that the downstream market price should exceed a floor equal to the sum of three costs: (i) the monopolist's price of the upstream input to the rivals, $w$; (ii) the cost of other inputs to the downstream process, $s$; and, (iii) the cost to rivals that results from the monopolist's discrimination, $r$.

Therefore, I have shown that for downstream rivals to survive, the imputation floor price has to exceed the traditional imputation floor of $w+s$ by the artificial cost $r$ imposed on the rivals by the monopolist. If the imputation floor is set at the traditional level of $w+s$, the independent firms will be foreclosed.

Proposition 5. The monopolist can use the strategy of raising downstream rivals' costs to circumvent traditional imputation floors and foreclose its rivals.

In light of Propositions 1-5, it is prudent policy for a regulator to set imputation floors reasonably higher than the traditional level of upstream input plus other

\footnotetext{
${ }^{15}$ Even in the absence of non-price discrimination strategies, such as the strategy of raising rivals costs, imputation cannot fully safeguard against price discrimination effects. Even if the integrated monopolist adheres to an imputation rule and charges itself as much as it charges others for the essential input, in the profit maximization of the integrated firm, the cost of using one more unit of this input is its true marginal cost, and not what the integrated firm charges others (and itself). Thus, since the integrated firm makes more profit for every unit of output than its rivals even when, under Cournot, they all sell at the same downstream price, the integrated firm in equilibrium has a higher scale of operation and can, for some range of fixed costs, foreclose its opponents. Moreover, for an imputation policy to have the desired effect, full observability of costs is required - a condition that is unlikely to be fulfilled. This may be particularly difficult since typically firms do not have an incentive to accurately reveal their costs to the regulator.

${ }^{16}$ The results are even stronger when the downstream firms have to recover a positive fixed cost to survive.
} 
downstream costs, with the difference reflecting the degree to which the monopolist can artificially increase the costs of its downstream rivals through non-price discrimination.

\section{Concluding remarks}

I showed that a monopolist in an input market has a strong incentive to increase the costs of the rivals to its downstream subsidiary. Such action "softens" competition downstream and increases the profits of the vertically integrated monopolist. I have further shown that this result is true, even when the integrated monopolist's subsidiary has higher or lower costs than its downstream competitors. Moreover, I showed that the monopolist does not have an incentive to raise the costs to the whole downstream industry, but just to the rivals of its subsidiary. Thus, the monopolist has clear incentive for discriminatory action against its downstream rivals.

I have also showed that raising rivals' costs effectively circumvents traditional imputation rules, and allows the monopolist to foreclose its downstream rivals. In the presence of non-price discrimination, to be effective, imputation floors have to be adjusted upwards to account for the artificial costs imposed on the rivals.

The collection of these results raise significant concerns about the potentially anti-competitive effects of entry of local exchange carriers in long distance service. It also raises serious concerns for anti-competitive behavior of any vertically integrated firm that dominates a market for inputs that are essential to competitors (in some other market) of the integrated firm.

\section{Acknowledgements}

I thank Gary Biglaiser, Steve Levinson, Steve Martin, John Mayo, Matthew Nagler, Roger Noll, Marty Perry, Roy Radner, David Reiffen, Mike Riordan, John Sumpter, an anonymous referee and participants at seminar presentations at the Winter Meeting of the American Economic Association, the 1997 Telecommunications Policy Research Conference, the Summer Meeting of the Western Economic Association, the Federal Communications Commission, Stanford University, and the Stern School of Business for helpful comments and suggestions. Financial support from the Markle Foundation is gratefully acknowledged.

\section{References}

Beard, T.R., Kaserman, D.I., Mayo, J.W., 1996. Regulation, Vertical Integration, and Sabotage. Mimeo. Bernheim D., Willig, R., 1996. The Scope of competition in telecommunications. AEI Studies in Telecommunications Deregulation, Working Paper; October 25, 1996. 
Economides, N., 1998. Quality choice and vertical integration. International Journal of Industrial Organization, forthcoming.

Economides, N., 1996. The economics of networks. International Journal of Industrial Organization 14 (6), 675-699.

Economides, N., Lehr, W., 1995. The quality of complex systems and industry structure.In: Lehr, W. (Ed.), Quality and Reliability of Telecommunications Infrastructure. Lawrence Erlbaum, Hillsdale, 1995.

New Zealand Ministry of Commerce, 1995. Regulation of access to vertically-integrated natural monopolies

Sibley, D., Weisman, D., 1995. Competitive Incentives of Vertically Integrated Local Exchange Carriers. Mimeo.

United States Department of Justice, 1997. Petition by the United States for an order to show cause why respondent Microsoft Corporation should not be found in civil contempt, filed October 20, 1997. 